\title{
The False Consensus Effect: Deconstruction and Reconstruction of an Anomaly
}

Dirk Engelmann Martin Strobel

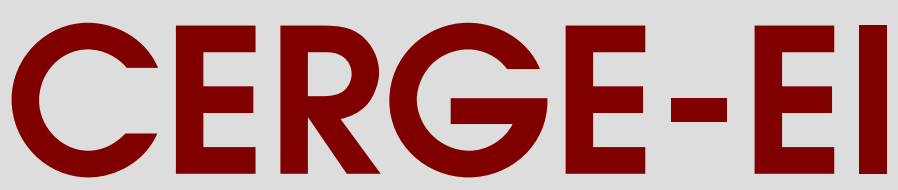

Charles University Center for Economic Research and Graduate Education Academy of Sciences of the Czech Republic Economics Institute 


\title{
The False Consensus Effect: Deconstruction and Reconstruction of an Anomaly*
}

\author{
Dirk Engelmann ${ }^{\dagger} \quad$ Martin Strobel ${ }^{\ddagger}$
}

August 25, 2004

\begin{abstract}
We present a striking example of the deconstruction and reconstruction of an anomaly. In line with previous experiments we show in a one-shot setting that the allegedly robust false consensus effect disappears if representative information is readily available. But the effect reappears if a small cognitive effort is required to retrieve the information. Most subjects apparently ignore valuable information if it is not handed to them on a silver platter. We conclude that the relevance of the false consensus effect depends on the difficulty of the information retrieval and that the underlying mechanism is an information processing deficiency rather than egocentricity. Moreover, we discuss the potential relevance of our findings for other well-known effects like the winner's curse and overconfidence.

Článek prezentuje pozoruhodný př́íklad rozložení a rekonstrukce anomálie. Pomocí jednorázového uspořádání v souladu s předchozími experimenty ukazuje, že údajně odolný efekt falešného konsensu mizí za předpokladu snadno dostupných reprezentativních informací. Efekt se ovšem znovu objevuje pokud je k vyhledání informací zapotřebí vynaložit byt' jen malé kognitivní úsilí. Většina subjektů podle zdání ignoruje hodnotné informace, pokud nejsou předloženy na stříbrném podnosu. Dovozujeme, že platnost efektu falešného konsensu závisí na obtížnosti vyhledání informací a že základním mechanismem jsou nedostatky ve zpracování informací spíše než sebestřednost. Kromě toho diskutujeme i potenciální platnost našich závěrů pro další dobře známé jevy, jako je například prokletí vítězů či př́lišná jistota.
\end{abstract}

Keywords: False Consensus, Information Processing, Anomalies, Experimental Economics JEL-Classification: C91, D83, D84

${ }^{*}$ We thank Marlies Ahlert, Andrew Austin, Dan Friedman, Jan Potters, and in particular Andreas Ortmann for helpful comments. Parts of this research were financed by the Deutsche Forschungsgemeinschaft (through Grant No. EN 459/1), METEOR, Maastricht University (through the research programme "kleinschalige stimulering onderzoek"), and an ESC postdoctoral fellowship from the CERGE-EI Foundation. The financial support is gratefully acknowledged. We are very grateful to the laboratory of experimental economics at the University of Bonn, and in particular to Heike Hennig-Schmidt, for their hospitality.

${ }^{\dagger}$ CERGE-EI, Charles University, Prague and the Academy of Sciences of the Czech Republic, P.O.Box 882, Politickych veznu 7, CZ 11121 Prague 1, Czech Republic, phone: +420-224 005 244, e-mail: dirk.engelmann@cergeei.cz.

${ }^{\ddagger}$ Department of Economics and International Institute of Infonomics, University of Maastricht, P.O. Box 616, 6200 MD Maastricht, The Netherlands, phone: +31 (0)43 38-83646, fax: +31 (0)43 38-84878, e-mail: Martin.Strobel@infonomics.nl. 


\section{Introduction}

Violations of the rationality postulates of economics, so-called choice anomalies, have received substantial attention by economists (see Camerer, 1995), because they question the fundamental tools of economic analysis. The relevance of anomalies for economic modeling, however, crucially depends on how well they translate into economically relevant situations, hence how robust they are to learning and to changes in institutions.

Friedman (1998) demonstrates that the so-called three-door anomaly can be constructed and deconstructed by the use of different experimental conditions. He argues that alleged anomalies "can be greatly diminished in appropriately structured learning environments" (p. 941) and that economists should hence focus on "which learning environments encourage or discourage specific kinds of anomalies ... [and] ... which institutions are sensitive to anomalous choice behavior" (p.942). ${ }^{1}$ In the present paper we address this issue by way of an important example, the false consensus effect. We have demonstrated in Engelmann and Strobel (2000) that this effect can be made to disappear by a prominent presentation of representative information. In the present study, we confirm that this deconstruction works even in a one-shot setting. We also demonstrate how the effect can be reconstructed. It shows up clearly if the retrieval of this information requires some effort.

Considering the social psychology literature, the 'false consensus effect', going back to Ross et al. (1977), appears to be a well-established phenomenon. Indeed, already Mullen et al. (1985) report 115 studies which show a false consensus effect. Most of the studies employed a definition similar to that used by Mullen et al. (1985):

False consensus refers to an egocentric bias that occurs when people estimate consensus for their own behaviors. Specifically, the false consensus hypothesis holds that people

\footnotetext{
${ }^{1} \mathrm{~A}$ discussion of the systematic construction and deconstruction of various choice anomalies is presented in Hertwig and Ortmann (2001) and Gigerenzer (1991).
} 
who engage in a given behavior will estimate that behavior to be more common than it is estimated to be by people who engage in alternative behaviors. ${ }^{2}$

In short, those people who choose $\mathrm{A}$ from a set of options $\{\mathrm{A}, \mathrm{B}\}$ expect a higher frequency of $\mathrm{A}$ choices than those who choose B. According to Dawes (1989, 1990), however, this type of definition does not justify the label 'false'. He argues that it is perfectly rational to use the information about one's own decision in the same way as the information about any other randomly selected sample of size one. The effect is only false if too much weight is assigned to one's own decision. We will therefore refer to the effect defined above as a consensus effect and use the following definition of a false consensus effect which is both stricter and more appropriate:

A (truly) false consensus effect is considered to be present if people, when forming expectations concerning other people's decisions, weight their own decision more heavily than that of a randomly selected person from the same population.

Put differently, people exhibit a false consensus effect if among those with the same total information (i.e. including the information about their own decision) the estimates are biased in the direction of their own decision, i.e. those who choose behavior A expect a higher frequency of A choices than those who choose B. In contrast to the traditional definition, this definition implies that a false consensus effect can be considered as a bias in a Bayesian framework. A consistent bias of expectations in the direction of a decision maker's own decision or preferences would have an impact on economic interaction whenever decisions are influenced by these expectations, most notably perhaps in financial markets (note the relation to overconfidence, a similarly debated effect,

\footnotetext{
${ }^{2}$ For example, in the study by Ross et al. subjects were asked to walk around campus wearing a sandwich board saying "Repent". Those who agreed estimated that $63.5 \%$ of their peers would do so, while those who refused expected only $23.3 \%$ to agree.
} 
that has received much more attention). ${ }^{3}$ Detecting conditions under which such a bias occurs as well as quantifying the bias would greatly improve our ability to predict human behavior.

When the strict definition of the false consensus effect is applied, results from social psychology experiments are rather ambiguous. ${ }^{4}$ They usually do not allow for a straightforward test and some aspects of the design appear problematic (see Dawes, 1990 and Engelmann and Strobel, 2000 for a more detailed discussion). Studies by economists that were not designed to explicitly test for a false consensus effect appear to provide evidence in its favor, but usually based on the traditional, inappropriate definition (e.g. Selten and Ockenfels, 1998; Jacobsen and Sadrieh, 1996; Charness and Grosskopf, 2001). Heijden et al. (2003) test for a consensus effect in a survey experiment. They find a clear consensus effect, which, however, decreases significantly if arguments concerning the issue at hand and financial incentives are provided. Their design does not allow them to conclude whether the consensus effect is indeed a false consensus effect.

Explicit tests for a false consensus effect, run in accordance with the sacred principles of experimental economics (i.e. no deception and clear financial incentives), are provided by Offerman et al. (1996) and by Engelmann and Strobel (2000). Offerman et al. (1996) examine the presence of a false consensus effect in a public good experiment by comparing estimates given by participants and observers and find no indication of a false consensus effect. In Engelmann and Strobel (2000) subjects make 16 simple binary choices (e.g. they decide whether they want to receive their payment right after the experiment or one month later with $10 \%$ interest). In half of the cases, they are then informed about the choices of four randomly selected subjects from the group of 16 taking part in each session, before they are asked to estimate the choice of the remaining eleven subjects. We find that subjects attach a lower weight to their own choice than to the information they are presented with in all five sessions, providing significant evidence exactly contrary to a false consensus effect. On the other hand, we find significant evidence for a consensus effect, i.e.

\footnotetext{
${ }^{3}$ Forsythe et al. (1992) find evidence for a (false) consensus effect in a political stock market.

${ }^{4}$ For a recent critical account of the literature on the false consensus effect see Krueger and Funder (2004).
} 
subjects indeed consider their own choice as informative about others' choices, but as less, not more, informative than the choices of randomly selected other subjects.

A common feature of Offerman et al. (1996) and Engelmann and Strobel (2000) is that the available information is in a way handed to subjects on a silver platter. It is highly prominent and requires absolutely no effort on part of the subjects to retrieve. This is even more the case in Engelmann and Strobel (2000) where we explicitly provide subjects with a list of others' choices than in Offerman et al. (1996) where subjects observed the behavior in repeated games and hence had to keep track of the aggregated data themselves. ${ }^{5}$ Hence the false consensus effect can easily be deconstructed by the provision of highly prominent representative information. This, however, does not necessarily reflect the most realistic or relevant scenarios. In contrast, outside the laboratory, one might often have to make a small cognitive effort to find out about others' choices. And in these cases people might rely more on their own choice as a guideline than on available information because they either do not want to exert the effort of retrieving the information or such information is perceived as less relevant. The deconstruction might hence work under extreme conditions, but the effect might still be relevant in other cases. The question is how easily it can be reconstructed in the same framework where it has been deconstructed.

To investigate whether a false consensus effect depends on the cognitive effort needed to retrieve information, we compare two treatments in a simple one-shot experiment. Subjects first choose whether all four subjects in their group will play a lottery and then estimate how many of the twelve subjects in the three other groups of the session have chosen the lottery. The treatments differ in the form how information about the choice of the three other members of their own group is provided before subjects state their estimate. In one treatment, the information is provided explicitly. In the second treatment, information is only implicitly provided in the form of the

\footnotetext{
${ }^{5}$ In their design, however, an observer was linked with a specific participant making the choices of the participant highly prominent for the observer. Thus while the information about other subjects is less prominent than in Engelmann and Strobel (2000), the information that is crucial for their test is highly prominent as well.
} 
payoff of the lottery stage. This stage was designed, however, in a way that made the decisions of the other three subjects easily retrievable from the payoff, once a subject has realized that the payoff conveys this information.

In a third treatment, subjects estimate the choice of the three other members of their group before results from the lottery stage are provided, and then after having received detailed results of the lottery stage they again estimate the choice of the remaining twelve subjects. The first estimate replicates classical consensus experiments without provision of information, testing whether subjects' beliefs are biased towards their own choice in the absence of other information. Comparing the second stage estimates in this treatment with those in the explicit information treatment allows us to test whether beliefs are sticky, i.e. whether subjects' beliefs are biased towards their own choice even after they received conflicting information if they expressed their beliefs before.

For all estimates substantial monetary incentives were provided. To the best of our knowledge the present experiment is the first to systematically study the false consensus effect under varying information conditions.

Our main hypothesis is that subjects make less use of implicit information than of explicit information. Hence the estimates in the implicit information treatment should be more in line with a false consensus effect than in the explicit information treatment because subjects should rely more on their own choice as benchmark in the former than in the latter. More specific hypotheses are that estimates in the explicit information treatment run counter to a false consensus effect, whereas they are in line with a false consensus effect in the implicit information treatment. Put differently, providing explicit information is sufficient to deconstruct the effect, while making the information implicit suffices to reconstruct it.

Our results provide clear support for our hypotheses. In all but one of the groups in the explicit information treatment results are in the opposite direction to a false consensus effect, in all groups in the implicit information treatment results are in line with a false consensus effect. This shows that most subjects are unwilling or unable to use information that is not handed 
to them on a silver platter. It appears to us that in the implicit information treatment it does not occur to many subjects that the other three subjects' choices are valuable information and that this information is rather easily available, while the prominent information in the explicit information treatments is recognized as valuable information by virtually all subjects (or leads them to unconsciously update their beliefs). In the third treatment, all subjects update their beliefs as expected and beliefs are not sticky, because although first stage estimates are clearly biased towards the subjects' own choices, second stage estimates are not more biased towards their own choices than in the explicit information treatment.

The remainder of this paper is structured as follows. In the next section we describe the experimental design. Section 3 contains the experimental results, followed by the conclusion.

\section{Experimental Design}

The computerized experiments were run in the laboratory of experimental economics at the University of Bonn in November and December 2002. We used the tool kit $z$-Tree, developed by Fischbacher (1999) for creating the experimental software and running the experiments. The subject pool comprised 90 economics students, 14 law students, and 24 students of 20 other disciplines.

We conducted three treatments: IM with information provided implicitly, EX with information provided explicitly, and BA with estimates given both before and after the explicit provision of information. In each of eight sessions (three in EX, three in IM, and two in BA), 16 subjects participated.

Subjects gathered in a separate room next to the laboratory. After a short welcome they were randomly placed at isolated computer terminals in the laboratory where they received written instructions for the first stage of the experiment (for translated instructions see the Appendix). The crucial issues were then summarized by the experimenter. Instructions for the second stage of the experiment were provided on the computer screen after the first stage was completed. 


\begin{tabular}{cc}
\hline \hline \# Lotteries & Potential payoffs \\
\hline 0 & 10 \\
1 & 8,18 \\
2 & $6,16,26$ \\
3 & $4,14,24,34$ \\
4 & $2,12,22,32,42$ \\
\hline
\end{tabular}

Table 1: Potential payoffs dependent on the number of lotteries chosen in a group.

The experiment consisted of only one period, divided into two stages. The 16 participants were split into four groups of four, but the subjects did not know which of the other 15 subjects were in their group.

Each subject started the experiment with an endowment of 10 Euro. In the first stage of the experiment, subjects decided whether to conduct the following lottery. If they chose yes, 2 Euro were taken from each of the subjects in their group including themselves and then a prize of 10 Euro was randomly allocated to one of them. For each subject who chose yes, a separate, independent lottery was conducted. Table 1 shows the number of lottery choices in the group and the resulting potential payoffs.

If, for example, two subjects chose a lottery, payoffs could be 6, 16, or 26 Euro (to be precise, they were either 6 for two subjects and 16 for the other two, or 26 for one and 6 for the other three subjects). Note that each choice of a lottery increases the total payoff by 2 Euro to encourage subjects to choose the lottery (as will become clear in a second, we wanted to maximize the probability of having both yes and no choices in each group of four subjects).

We chose this game because it is relatively easy but not trivial to infer the other subjects' choices from one's own payoff after the first stage. While it may be difficult for subjects to realize that their payoff conveys complete information about the other subjects' choices (and we will argue below that this is where subjects fail), once they have realized this, it is easy to derive 


\begin{tabular}{ccc}
\hline \hline & \multicolumn{2}{c}{ Information } \\
& implicit & explicit \\
\hline estimates given after feedback only & IM & EX \\
estimates given both before and after feedback & & BA \\
\hline
\end{tabular}

Table 2: Overview of the Treatments

the information from the payoff. For example, assume that a subject has chosen the lottery and obtains a payoff of 16 Euro. Then this subject can infer that she has won a lottery and that two lotteries have been played. Since she has chosen the lottery, exactly one other subject has chosen the lottery as well. If a subject has not chosen the lottery and obtains a payoff of 24 he can infer that he has won two lotteries, that three lotteries have been conducted and that hence all other subjects have chosen the lottery.

Another reason we chose this game is that there is no obvious fair or unfair choice in the game so that we can preclude that social norms bias the results towards conformity (i.e. that a subject would choose the lottery when she expects other subjects to do so because she considers it fair, as would be the case in, e.g., public good games).

In treatments IM and EX, after making their choice subjects received feedback about the results of the first stage. In IM they only learned their payoff from the first period. In EX they were given detailed feedback about the number of lottery choices in the first stage and how many of these lotteries they had won. Treatment BA differed from EX by first asking subjects about their estimate for the number of lotteries chosen by the other three subjects in their group. For an exactly correct guess they received 5 Euro.

In the second stage of the experiment, the task was to estimate how many lotteries the twelve subjects in the other three groups of the present session had chosen. For an exactly correct guess a subject received 15 Euro, certainly enough to encourage a subject to think hard and not to 
ignore potentially relevant information. This stage was identical in all treatments. See Table 2 for an overview of the treatments.

After having received feedback about the correct guess and their payoff, subjects were asked to fill in a short questionnaire. Eventually they were called upon one by one to receive their payment in a separate room. The sessions took between 40 and 50 minutes altogether. Average earnings were 13.88 Euro.

\section{Experimental Results}

All four subjects in one group have the same information after receiving the feedback from the first stage. If each subject considers his or her own choice to be equally informative as the choices of the other three subjects (which appears to be rational) then there should be no systematic difference between the estimates given by subjects who chose the lottery and by those who did not. In contrast, the false consensus hypothesis states that subjects will consider their own choice to be more informative than the information about the other subjects in their group. This would imply that the subjects who chose the lottery will estimate a higher number of lottery choices among the twelve remaining subjects than the subjects who did not choose the lottery. Hence we can say that estimates in a group of four subjects correspond to a false consensus effect if the difference between the average estimate given by the subjects who chose the lottery and the average estimate given by the subjects who did not choose the lottery is positive. ${ }^{6}$ This measure is not defined for homogeneous groups where all subjects make the same choice. This is why we tried to choose experimental parameters that would provide roughly equal probabilities of choices for and against the lottery in order to maximize the number of heterogeneous groups. (We actually

\footnotetext{
${ }^{6}$ We cannot tell whether the subjects who chose the lottery, or those who did not, or both, exhibit a false consensus effect in this case, because we do not know their prior beliefs and hence do not know the result of correct Bayesian updating for the information given, but it is clear that at least one side does.
} 
came relatively close to achieving this goal, the overall rate of choices in favor of the lottery is $61 \%)$.

We now come to the main result for the explicit information treatment.

Result 1: In treatment EX, when forming beliefs, subjects weight their own choice significantly less than the information about other subjects' choices (that is, they make too little use of the knowledge of their own choice), opposite to the false consensus hypothesis. Hence prominent information is sufficient to deconstruct the false consensus effect.

Immediate support for Result 1 is provided in Table 3, which shows the number of lotteries chosen in each of the twelve groups in treatment EX, the average estimate given by subjects who chose and who did not choose the lottery as well as the difference between these estimates. Unfortunately, in groups 10 and 12 there was one subject that had participated in a previous session. There appear to be two ways to handle this problem. The first is to exclude those groups completely from the analysis, the second is to exclude the repeat subjects in the computation of average estimates in the respective groups (since the only thing a subject learns about another subject is his or her choice in the first stage, there is not really a danger of a repeat subject spoiling the group, so this procedure appears to be sufficient). The first approach appears to be the more careful one. It does, however, only make our results stronger, in a way rewarding us for a mistake in the procedures. Hence we follow both approaches.

As Table 3 shows, there are nine heterogeneous groups and in only one of them (12) the result is in line with a false consensus effect, i.e. the average estimate of lottery choices given by the subjects who chose the lottery is larger than the average estimate given by the subjects who did not. In seven of them the effect is in the opposite direction, and in the last (10) there is a tie (if we include the repeat subject, the difference is negative as well). ${ }^{7}$

Since different groups in one session do not interact, we can treat each group of four as a statistically independent observation (more precisely, the aggregate measure we use in each group

\footnotetext{
${ }^{7}$ None of the results we report changes if we replace average estimates with median estimates.
} 


\begin{tabular}{|c|c|c|c|c|}
\hline Group & \# lotteries chosen & average estimate Yes & average estimate No & difference Yes - No \\
\hline 1 & 4 & 11.25 & n.a. & n.a \\
\hline 2 & 3 & 8.33 & 9 & -0.67 \\
\hline 3 & 1 & 3 & 6.67 & -3.67 \\
\hline 4 & 3 & 8 & 9 & -1 \\
\hline 5 & 3 & 8.67 & 10 & -1.33 \\
\hline 6 & 1 & 0 & 5.33 & -5.33 \\
\hline 7 & 4 & 10.5 & n.a & n.a \\
\hline 8 & 3 & 8.67 & 10 & -1.33 \\
\hline 9 & 4 & 10.5 & n.a. & n.a. \\
\hline $10^{*}$ & 1 & 4 & $4.33 / 4$ & $-0.33 / 0$ \\
\hline 11 & 3 & 8.67 & 10 & -1.33 \\
\hline $12^{*}$ & 1 & 6 & $4.67 / 4.5$ & $1.33 / 1.5$ \\
\hline
\end{tabular}

Table 3: Results for treatment EX. The columns show from left to right the group number, the number of lotteries chosen in that group, the average estimate (from a possible range of 0 to 12) given by the subjects who chose the lottery, that given by subjects who did not, and the difference between these two estimates. If this difference is positive it corresponds to a false consensus effect. Group numbers with an asterisk indicate groups with repeat subjects. The second number in the fourth and fifth columns for these groups indicates the estimates and differences if these subjects are excluded. 
is the difference between the average estimates given by those who chose the lottery and by those who did not). A Wilcoxon signed rank test (for the $H_{0}$ hypothesis that the estimates are equal) reveals that the tendency against a false consensus effect is significant at the $10 \%$ level ( $p=0.074$, two-sided; hence for a one-sided test, which can be argued is appropriate for our directed hypothesis, the difference is significant at the $5 \%$ level). ${ }^{8}$ Since the groups with the repeat subjects are those with a positive difference and a tie, the results are even clearer if we exclude these groups altogether $(p=0.017) .{ }^{9}$

Hence our treatment EX replicates, as expected, our results from Engelmann and Strobel (2000): subjects, when making estimates, give significantly more weight to information provided about other subjects' choices than to their own choice, if that information is prominent and available without any effort. In other words we have successfully deconstructed a belief anomaly. A natural question is whether the anomaly can be reconstructed by making the information retrieval more difficult. This question is answered by our implicit information treatment.

Result 2: In treatment IM, when forming beliefs, subjects weight their own choice significantly more than the information about other subjects' choices, in line with the false consensus hypothesis. Hence making information less prominent is sufficient to reconstruct the false consensus effect.

Table 4 shows the results for the twelve groups in treatment IM, with a structure identical to Table 3. The results are even clearer than in treatment EX. There are ten heterogeneous groups and in each of them the average estimate given by the subjects who chose the lottery is higher than the other subjects' average estimate, in line with a false consensus effect. Furthermore, in six of the ten groups the difference is substantial $(>3$, corresponding to more than $25 \%$ of the target group of twelve subjects).

\footnotetext{
${ }^{8}$ All tests are two-sided unless noted differently.

${ }^{9}$ Ignoring the problem of repeat subjects would also yield a stronger result $(p=0.042)$. Simple sign tests yield very similar $p$-values.
} 


\begin{tabular}{|c|c|c|c|c|}
\hline Group & \# lotteries chosen & average estimate Yes & average estimate No & difference Yes - No \\
\hline 1 & 1 & 7 & 5.33 & 1.67 \\
\hline 2 & 1 & 12 & 5.33 & 6.67 \\
\hline 3 & 3 & 7 & 5 & 2 \\
\hline 4 & 1 & 12 & 6.33 & 5.67 \\
\hline 5 & 1 & 8 & 3 & 5 \\
\hline 6 & 4 & 10 & n.a. & n.a. \\
\hline 7 & 1 & 11 & 4.33 & 6.67 \\
\hline 8 & 4 & 9.5 & n.a. & n.a. \\
\hline 9 & 2 & 8.5 & 4.5 & 4 \\
\hline 10 & 2 & 7.5 & 6 & 1.5 \\
\hline 11 & 2 & 9 & 5.5 & 3.5 \\
\hline 12 & 2 & 6.5 & 6 & 0.5 \\
\hline
\end{tabular}

Table 4: Results for treatment IM. The columns show from left to right the group number, the number of lotteries chosen in that group, the average estimate given by the subjects who chose the lottery, that given by subjects who did not, and the difference between these two estimates. If this difference is positive it corresponds to a false consensus effect. 
A Wilcoxon signed rank test reveals that this tendency in line with a false consensus effect is significant at the $1 \%$ level $(p=0.005$, two-sided). Hence this treatment confirms our hypothesis that subjects exhibit a false consensus effect if representative information is only implicitly provided. The extent of the difference between treatments EX and IM suggests that most subjects in IM simply do not come up with the idea of using the available information. The lower prominence of the available information in treatment IM is sufficient to reconstruct the false consensus effect.

Since we find a significant false consensus effect in treatment IM and a significant effect opposite to a false consensus in treatment EX, this already provides very strong support for our more modest main hypothesis that results in treatment IM are closer to a false consensus effect than results in treatment EX. For the sake of completeness, we provide the result of a Mann-Whitney test of the $H_{0}$ hypothesis that the differences between estimates given by subjects who chose the lottery and those who did not are not different in the two treatments. We can reject this $H_{0}$ hypothesis at the $0.1 \%$ level $(p=0.0004$ if we exclude the repeat subjects, $p=0.0006$ if we exclude the groups with repeat subjects). Thus already with a moderate number of independent observations we find very strong support for our main hypothesis.

Treatment BA provides further insights into the use of information. This treatment only differs from EX by the additional estimate subjects are asked to give before they get feedback on the results of the first stage. Table 3 shows the data in the same form as Tables 3 and 4, but in addition shows in the third and fourth column the estimates given in the first stage by the subjects who chose the lottery and those who did not and it shows in parentheses the estimates given by individual subjects both in the first and in the second stage (in the same order).

Result 3: In treatment BA, first-stage estimates exhibit a clear consensus effect, while secondstage estimates do not differ from treatment EX. Hence beliefs are not sticky.

The first result we observe is that estimates given in the first stage by subjects who chose the lottery are definitely higher than estimates given by subjects who did not. In particular, of 23 subjects who chose the lottery 21 expected that two or three of the remaining three subjects chose 


\begin{tabular}{cccccccc}
\hline \hline Group & \# lott. & 1st est. Yes & 1st est. No & Yes - No & 2nd est. Yes & 2nd est. No & Yes - No \\
\hline 1 & 3 & $2.33(3,2,2)$ & $2(2)$ & 0.33 & $8.67(9,9,8)$ & $10(10)$ & -1.33 \\
2 & 1 & $2(2)$ & $1(2,1,0)$ & 1 & $1(1)$ & $3.67(5,3,3)$ & -2.67 \\
3 & 3 & $2.33(2,3,2)$ & $1(1)$ & 1.33 & $7.67(7,8,8)$ & $10(10)$ & -2.33 \\
4 & 3 & $2.33(3,2,2)$ & $1(1)$ & 1.33 & $9.33(9,10,9)$ & $11(11)$ & -1.67 \\
5 & 2 & $2.5(2,3)$ & $1(1,1)$ & 1.5 & $7(7,7)$ & $5(5,5)$ & 2 \\
6 & 3 & $2.33(2,3,2)$ & $2(2)$ & 0.33 & $8(8,8,8)$ & $9(9)$ & -1 \\
7 & 4 & $1.75(1,2,2,2)$ & n.a. & n.a. & $10.25(9,11,10,11)$ & n.a. & n.a. \\
8 & 4 & $2.25(1,3,3,2)$ & n.a. & n.a. & $10.25(12,8,12,9)$ & n.a. & n.a. \\
\hline
\end{tabular}

Table 5: Results for treatment BA. The columns show from left to right the group number, the number of lotteries chosen in that group, the first-stage average (and individual) estimates given by the subjects who chose the lottery, the first-stage average (and individual) estimates given by subjects who did not, and the difference between these two estimates. If this difference is positive it corresponds to a consensus effect. The remaining three columns show the corrsponding data for second-stage estimates. A positive difference here corresponds to a false consensus effect. 
the lottery as well, whereas of nine subjects who did not choose the lottery, six expected that none or only one of the other three subjects did. In all of the six heterogenous groups the average estimate given by the subjects who chose the lottery is higher than that given by the other subjects. This yields clear and significant evidence in favor of a consensus effect, corresponding to the traditional, inappropriate, definition of a false consensus effect (Mann-Whitney test, $p=0.001$ ). ${ }^{10}$ Hence we replicate the results of classical results on the (false) consensus effect. This implies that the deconstruction of the false consensus effect in treatment EX is indeed due to the availability of prominent information (and the appropriate definition of the effect) and not to other aspects of our design that deviate from most studies in psychology, as for example, the monetary incentives we provide.

The second result of treatment BA is that the estimates given after the distribution of information differ again in the direction opposite to a false consensus effect, i.e. the average estimates given by subjects who chose the lottery are lower than those given by the other subjects in five of the six groups. This difference fails to be significant (Wilcoxon signed rank test, $p=0.173$ ). If, however, we consider treatments EX and BA together (which appears appropriate, because in both treatments subjects had the same information presented in similar prominent ways after the first stage), the second stage estimates indeed are significantly different (Wilcoxon signed rank test, $p=0.025$, where we again excluded in EX the repeat subjects from the averages). This supports previous experimental research that with readily available representative information, subjects do not exhibit a false consensus effect, but just the opposite: they give more weight to this information than to their own choice. ${ }^{11}$ The new aspect we learn from treatment BA is that

\footnotetext{
${ }^{10}$ Note that we can apply the test to the individual first-stage decisions because they are independent. But even if we use the differences of average estimates in each group as in the other tests, the result is still significant (Wilcoxon signed rank test, $p=0.027)$.

${ }^{11}$ Considering EX and BA jointly as treatments with explicit information we can, of course, again reject the $H_{0}$ hypothesis that the differences between estimates given by subjects who chose the lottery and by those who did not
} 
this result is not changed if subjects are already asked for an estimate before they receive the information, although they clearly show a consensus effect at that stage. Hence subjects are not reluctant to update their beliefs substantially as a result of new information. ${ }^{12}$

Indeed it is very informative to study the updating of individual subjects' beliefs. Since in the first stage subjects estimate how many of three others chose a lottery and in the second stage how many of 12 did so, a simple projection of the first to the second estimate would imply multiplying the first estimate by four. We can hence say that a subject updates his or her belief downwards if the second stage estimate is smaller than four times the first stage estimate, updates it upwards if the second stage estimate is larger than four times the first stage estimate and does not update if the second stage estimate is exactly four times the first stage estimate. We would expect a subject to update downwards if the first stage estimate was too high and to update upwards if it was too low.

We find that updating is always in the correct direction. All eight subjects whose first stage estimate was too high update downwards, all 13 whose first stage estimate was too low update upwards and of the 11 who were correct, five do not update, while three updated upwards and three downwards. See Figure 1 which illustrates how the error in the first stage is negatively correlated with the updating of estimates from the first to the second stage.

Of course, part of this result is driven by a regression to the mean, because naturally it was above-average estimates that were too high and below-average estimates that were too low. However, more than half of the subjects, 17 out of 32, gave a first stage estimate of 2 and hence if we restrict the analysis to this subset, results are not driven by a regression to the mean. Of these are not different in treatments with explicit information and in treatments with implicit information (Mann-Whitney, $p=0.0001)$.

\footnotetext{
${ }^{12}$ The differences between estimates given by subjects who chose the lottery and by subjects who did not, are far from significantly different between EX and BA (Mann-Whitney, $p=0.721$ ), and in fact the tiny difference is in the direction of even less false consensus in BA, inconsistent with a hypothesis of stickiness of beliefs.
} 
17 subjects, for three this estimate turned out to be too high and they all updated downwards, for six it was too low and they all updated upwards, and of the eight who were correct, three updated upwards and one downwards. ${ }^{13}$ Thus overall subjects clearly adapt their beliefs in line with new information, even if they had to express their beliefs before.

Glancing over the results for treatment IM, one might wonder whether subjects take the information into account at all. An ANOVA test for the hypothesis that the average estimate in the group is independent of the total information (conducted separately for the subjects who chose the lottery and those who did not) reveals a level of significance $p>0.27$ for the subjects who chose the lottery and $p>0.67$ for the subjects who did not choose the lottery. Hence the information has no clearly discernible impact on the estimates. In contrast, in EX the estimates depend on the information at $p<0.001$ both for subjects who chose the lottery and for those who did not and in BA the levels of significance are $p<0.002$ for the subjects who chose the lottery and $p<0.01$ for those who did not. Hence if information is explicitly given it clearly influences the estimates. We summarize this in the following result.

Result 4: Explicit information has a significant impact on estimates, while implicit information has not.

Our main results are also supported by linear regressions where we regress the estimate given by a subject in the second stage on the total number of lotteries chosen in his or her group and his or her own choice. In IM the effect of the total number of lotteries in the group is positive but far from significantly so $(p>0.5)$, while the effect of the subject's own choice is highly significant and positive $(p<0.001)$, in line with the false consensus hypothesis. In contrast, in EX and BA

\footnotetext{
${ }^{13}$ For subjects who stated extreme estimates, updating upwards or downwards can also result from rounding. For example, if the mode of the belief was at $90 \%$, a subject would guess 3 in the first stage, but 11 , and not 12 , in the second stage, and hence be considered to update downwards. This bias in favour of the observation that subjects always update in the right direction does not, however, apply to the 17 subjects who stated an estimate of 2 in the first stage.
} 


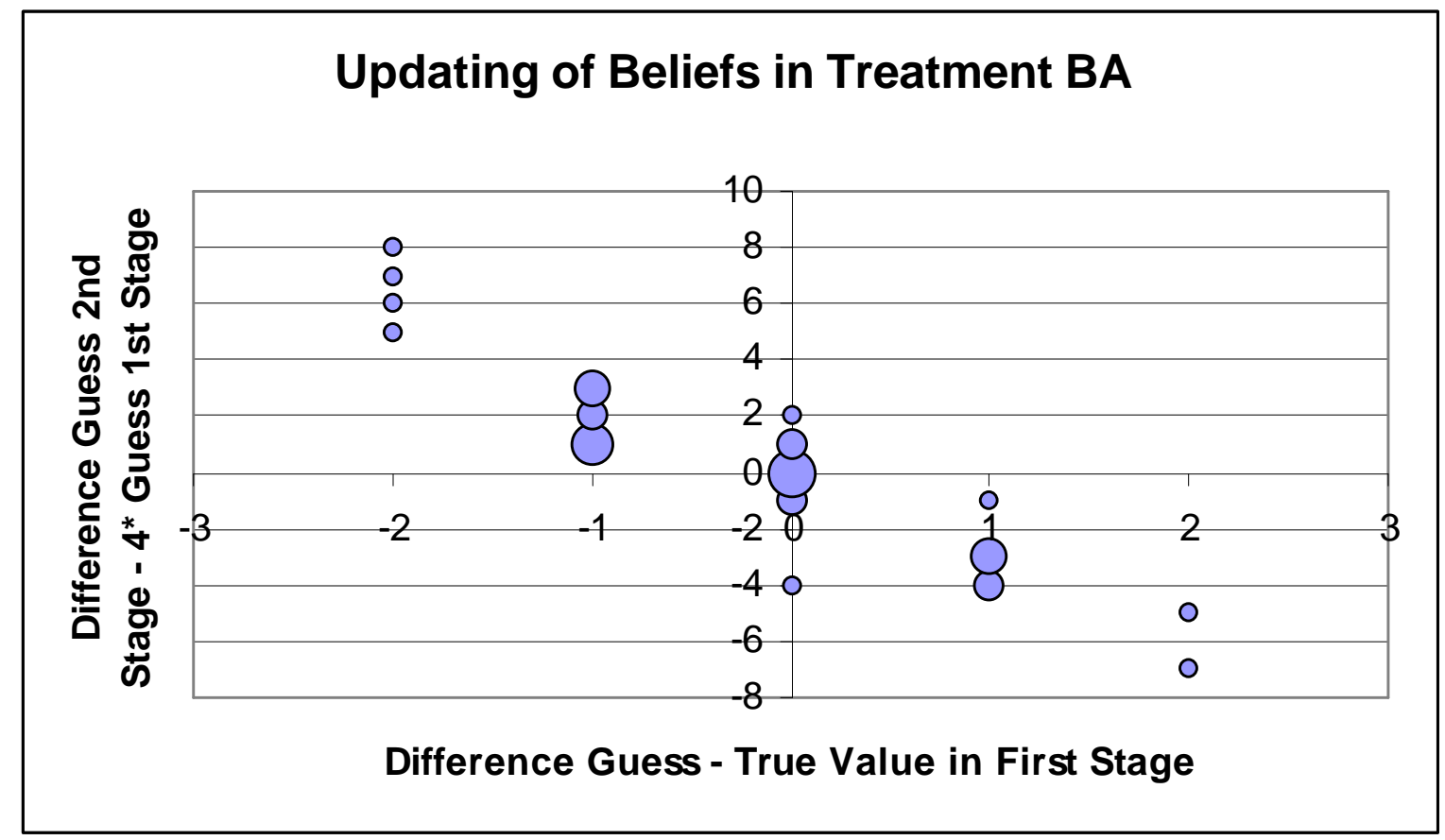

Figure 1: Updating of estimates in treatment BA. The $\mathrm{x}$-axis shows the difference between a subject's estimate in the first stage and the true value, i.e. by how much the estimate was too high. The $y$-axis shows the difference between the second stage estimate and a simple projection of the first stage estimate to the second stage task, which is achieved by multiplying the first stage estimate by four. This is an estimate of the extent of updating. The size of a bubble shows how often the corresponding combination occurred.

the effect of the total number of lottery choices is highly significantly positive $(p<0.001)$, but the effect of the subject's own choice is significantly negative $(p<0.05$ in $\mathrm{EX}$ and $p<0.1$ in $\mathrm{BA})$. This implies that given the same total information, subjects who chose the lottery give a lower estimate, opposite to the false consensus hypothesis. Note that this negative weight does not imply that the subjects exhibit a false uniqueness effect, i.e. assume that other subjects are different from them. This would be the case if their own choice had a negative weight when conditioning on the information about the other subjects. Doing this, however, the effect of a subject's own choice is 
significantly positive $(p<0.1$ in $\mathrm{EX}$ and $p<0.01$ in $\mathrm{BA})$, hence in both treatments subjects also base their decision on their own choice. ${ }^{14}$

In post-experimental questionnaires, there is interestingly not a dramatic difference in the number of subjects who explicitly mention that they used the number of lottery choices in their group as an input for their estimate (17 out of 48 in EX, 11 out of 48 in IM, and 7 out of 32 in BA). Apparently the number of subjects who are completely aware of the fact that this is a rational way to proceed does not differ substantially between the treatments. The number of those, however, who use the information but do not consider this crucial enough to mention it, and possibly the number of those who are not even aware that the information influences their beliefs, appears to be much higher with explicit information. One might infer that the beliefs of a substantial share of subjects are influenced by explicit information without a conscious updating process, but that their beliefs obviously cannot be influenced by implicit information in the same way because this requires a conscious information retrieval. Since the questionnaires consisted only of an open question how subjects made their choices, we can only speculate how those who did not mention that they used the information conceived their estimates.

While we cannot preclude with certainty that subjects in treatment IM tried to infer the choices of the other subjects in their group but just made mistakes, we have at least indirect support that they rather failed to realize that they can infer this information and that it might be useful. Since it is more difficult to derive the information in treatment IM than to just read it in treatment EX, subjects who try to infer the information in treatment IM should take more time in the

\footnotetext{
${ }^{14}$ We also ran regressions including the number of lotteries that a subject had won. While this would not be a rational reaction, one might suspect that winning a lottery makes it appear more attractive and hence increases the probability that one would choose the lottery in the future and hence by a misguided projection leads to an increase in the subjective probability that others would choose the lottery. Contrary to this hypothesis, the number of lotteries a subject has won has a negative effect, though far from significantly so in all treatments $(p>0.5)$. Including this variable does not change any of the other results.
} 
second stage of the experiment than in treatment EX. We find the opposite. The average decision time in the second stage is 59 seconds in treatment IM, but 77 seconds in treatment EX and 101 seconds in treatment BA. According to a Mann-Whitney test using group averages as independent observations, the difference in decision times is significant between IM and $\operatorname{EX}(p<0.03)$ and IM and BA $(p<0.001)$ but only marginally significant between EX and BA $(0.06<p<0.07)$. While the longer decision time in EX (and in particular in BA) can be attributed to the more extensive feedback, the differences in decision times gives us no reason to believe that subjects in IM tried hard to infer the other subjects' choices from their payoff, but failed. Furthermore, among the eleven subjects in IM who mentioned that they used the number of lottery choices in their own group as an input for their estimate, ten derived this number correctly. They either stated this number explicitly or the procedure they described and their estimate are only consistent with a correct inference. Therefore, while errors in the process may have occurred, our data does not indicate that they were frequent enough to drive the results.

A possible objection against our design is that it might be biased against a false consensus effect. If subjects' preferred number of lotteries is not zero or four (e.g. when they like a high maximal payoff but at the same time want to secure a minimal payoff of 4 Euros), they should choose a lottery when they believe the others are not going to do so and vice versa, implying a negative relation between their own choice and their estimate. Indeed, in the questionnaires a few subjects expressed that they thought others would choose the lottery so they preferred not to do so themselves. The strong consensus effect we find in treatment BA, however, suggests that this bias is not very important. Apparently most subjects either want lotteries or not, but they do not prefer an intermediate number. Moreover, this makes the strong false consensus effect we found in treatment IM even more striking.

A final and somewhat puzzling observation is that, although subjects in treatments EX and BA make more use of the available information than in IM and do so in a rational manner, the overall hit rate is higher in $\operatorname{IM}(10 / 48)$ than in $\operatorname{EX}(6 / 48)$ and $\mathrm{BA}(3 / 32)$. Even the average 
deviation of the estimate from the correct number of lottery choices is lower in IM (2.71) than in EX (3.08) and about the same as in BA (2.72). ${ }^{15}$ This suggests that subjects in the explicit information treatments give too much weight to the information. On the other hand, use of the information tends to reduce the probability of estimates that are wide of the mark, because the variance of the deviations is lower in BA (3.95) and EX (5.54) than in IM (6.13). ${ }^{16}$

\section{Concluding Remarks}

We have presented an experiment investigating the dependence of a false consensus effect on the prominence of representative information. Subjects made a single choice whether or not to play a lottery within their group of four subjects and in the second stage gave an estimate how many of the twelve subjects in three other groups had chosen the lottery.

Our treatment EX where we give detailed feedback after the first stage confirms the result of previous studies (Engelmann and Strobel, 2000; Offerman et al., 1996) that there is no false consensus effect if representative information is highly prominent and retrievable without any effort. Indeed, there is even a significant effect in the opposite direction, indicating that subjects consider others' choices as more informative than their own. While the information is highly prominent in this treatment, it is less suggestive to use it when forming expectations than in Engelmann and Strobel (2000). In that study there was no apparent purpose for the information other than to be used as a guideline for the estimate, which was even highlighted by the repeated switch between periods with and without information. In treatment EX the information about the

\footnotetext{
${ }^{15}$ Heijden et al. (2003) find a similar puzzling effect. The accuracy of the estimates in their experiment decreases when financial incentives are provided.

${ }^{16}$ These results do not fundamentally change if we do not compare a subject's estimate with what would have been the correct estimate for that particular subject, but with the correct estimate averaged over all subjects in all treatments who have the same information. This measure takes into account effects due to the random composition of sessions.
} 
other subjects' choices is well motivated by giving a more detailed explanation how the first-stage payoffs resulted, making it less apparent that the use of this information was the crucial question. Hence the results from treatment EX are stronger than our previous ones.

In contrast, in our treatment IM where the information about other subjects' choices can only be retrieved from the payoff in the first-stage game, we find clear and significant evidence in favor of a false consensus effect. In all groups estimates of the number of lotteries chosen by the participants outside their own group are higher for subjects who chose the lottery themselves than for those who did not. We conclude that the false consensus effect can be deconstructed by providing prominent representative information, and it can be reconstructed by reducing the prominence of this information.

Treatment BA finds a clear consensus effect in the estimates given by subjects in the first stage but again a clear effect opposite to a false consensus effect in the second stage after receiving feedback on the first stage. This indicates that subjects do not feel bound by their first estimate and are happy to update their beliefs if they receive conflicting evidence. Indeed the updating of beliefs after receiving information is always in the expected direction. The fact that we find a clear consensus effect without information but an equally strong effect after receiving information that runs counter to a false consensus effect suggests that subjects consider themselves to some degree representative of the population but consider randomly sampled information to be more representative. They appear to be thinking something like "others are like me, but others are more like others than I am."

Ex-post our results may appear not to be surprising. The extent of the treatment differences is, however, great and a claim that such a dramatic shift due to reduced prominence of the information is exactly what should be expected appears to us as evidence of a hind-sight bias. The treatment effect is underlined by the rather substantial monetary incentives to provide a correct estimate (15 Euro) and the fact that obtaining the information in treatment IM was relatively easy. To be more precise, once a subject has realized that her own payoff provides herself with complete 
information about all the choices in her group, infering this information is easy, while realizing that the information is available is a more difficult task. ${ }^{17}$ It appears to us, indeed, that most subjects simply do not come up with the idea at all that they can retrieve the other subjects' choices from the first-stage outcome ${ }^{18}$ or that they do not realize that this information is valuable if it is not explicitly provided.

The important implication is that we should not rely on subjects knowing (and using their knowledge) what we know they can know. Even if knowing the game and the outcome is enough to derive the other players' choices, this does not mean subjects come up with the idea to work backwards. ${ }^{19}$ In contrast, they may ignore valuable information and hence rely more on clues like their own choice, giving rise to distortions of expectation like the false consensus effect. Presentation of information can have dramatic impact. Highly prominent presentation can imply that it dominates other valuable information. One might, for example, argue that in the explicit information treatments information about the other subjects' choices is, because it is new, more prominent than the information about the subject's own choice and thus explain the underweighting of the latter. Implicit presentation of information, in contrast, can imply that it is widely ignored.

The false consensus effect, when it shows up, may in fact not be, as the psychology literature suggests, an "egocentric bias", but rather an "ignoring non-prominent information" bias, possibly caused by what has been labeled the "availability heuristic". This implies that the false consensus

\footnotetext{
${ }^{17}$ This is confirmed by the observation that among the eleven subjects in IM who mentioned that they used the number of lottery choices in their own group as an input for their estimate, ten derived this number correctly. Furthermore, the analysis of decision times is not consistent with the hypothesis that the subjects in IM tried to derive the information from the payoff, but failed.

${ }^{18}$ Note that the instructions contained two examples how payoffs depend on the number of lottery choices in the group, which indicates that the reverse process is possible as well.

${ }^{19}$ As a consequence, in repeated games learning might depend crucially on whether players receive explicit or implicit feedback about other players' choices.
} 
effect is not really about consensus. It is only an implication for specific questions (namely those concerning consensus estimates). The underlying bias appears to be more fundamental, namely on the level of deficient processing of information that is not highly prominent, coupled with more or less rational updating, given the limited information one is aware of. The effect should hence appropriately be called the "Oh, you have to tell me that something you said contains some useful information" effect. The flip-side of this effect seems to be the over-weighting of highly prominent information. $^{20}$

This effect might also be partly responsible for other phenomena, for example the winner's curse. While a bidder's own signal and the distribution of the value of the object to be auctioned off are usually highly prominent, the fact that winning the auction allows some conclusions about the other bidder's signals is not prominent. Or, put differently, the information about a bidder's own signal is explicit, while that about the other bidders' signals is only implicit. As most of the subjects in our experiment apparently do not come up with the idea that their payoff from the first stage conveys information about the behavior of the other subjects in their group, bidders in a common value auction apparently tend to ignore that winning the auction implies an upper bound on the signal of the other bidders.

Ignoring non-prominent information is also a potential cause for overconfidence in financial markets. While their private information is explicitly given and hence highly prominent to traders, the representative information of other traders cannot be directly observed and is only implicitly provided through the observation of the other traders' choices (which, of course, requires correct

\footnotetext{
${ }^{20}$ This is what apparently happens in treatments EX and BA. The results we find in these should not be mistaken for what can be called a false uniqueness effect, i.e. the belief that others tend to be different than one's self. Such a belief would imply that subjects give negative weight to their own choice in the estimation. This is not what we find, we only find that the weight given to the own choice is smaller than that given to the information about others' choices.
} 
assumptions concerning their strategies). As a consequence traders rely too heavily on their own information and behave as if they consider their own information as more accurate then the others'.

One would naturally like to know how difficult it is to deconstruct this information processing anomaly by, e.g., learning. Our experimental setup, however, does not allow for repetition (feedback across rounds would be more valuable than the information provided in any single round, thus subjects should learn to essentially ignore the information) and hence other designs are necessary. Other means of deconstruction might be substantially higher incentives or hints in the instruction that non-prominence of information does not mean non-existence, i.e. that it pays to look for valuable information also under the silver platter. Slowing the decision process down, for example by allowing subjects to enter the estimate only a few minutes after they were provided with the feedback and asked the question, might also encourage them to search more intensely for additional useful information.

Slembeck and Tyran (2004) demonstrate that the three-door anomaly can be almost completely eliminated with repetition if the environment allows for communication or competition, factors that might also reduce the ineffective processing of non-prominent information. Similarly, PalaciosHuerta (2003) confirm the results of Friedman (1998) that learning greatly diminishes the threedoor anomaly and finds in addition that higher ability (measured primarily in terms of SAT scores and GPA), larger incentives and communication between runs lead to faster learning. ${ }^{21}$

Our results concerning the false consensus effect are well in line with results on other biases and fallacies. For example, Koehler (1996) reviews the literature on the base rate fallacy and suggests "that a base rate has its greatest impact in tasks that (a) are structured in ways that sensitize decision-makers to the base rate, (b) are conceptualized by the decision-maker in relative frequentist terms, (c) contain cues to base rate diagnosticity, and (d) invoke heuristics that focus attention on the base rate." In our experiments, parallels to points (a) and (d) appear to be at

\footnotetext{
${ }^{21}$ Interestingly, less able subjects profit more from social interaction, indicating that it leads to learning spillovers from the more to the less able subjects.
} 
work. Subjects are apparently more sensitive to the explicitly provided information in EX than to the implicitly provided information in IM. The explicit information might also invoke simple heuristics (e.g. simply multiplying the information about one's own group by three). Krueger and Funder (2004) criticize the focus of social psychological research on errors in decision making and call for a balanced approach that investigates the conditions when biases occur and when they do not. Our study provides just such an investigation for the false consensus effect.

From a general perspective, the present experiment (in conjunction with our previous results in Engelmann and Strobel, 2000) presents an example of how cognitive biases can be made to disappear and reappear with the aid of variations in the design that might appear minor at a first glance. Our results are in fact more striking than those of Friedman (1998) for the three-door anomaly, because our experiment was one-shot and hence the alleged anomaly was not reduced by learning, but disappeared completely just by presenting representative information in a highly visible way. The anomaly could be made to reappear by making this information more difficult to retrieve. Our interpretation of this reappearance is that the underlying mechanism of the anomaly is not, as has been suggested, egocentricity, but a deficiency in information processing.

\section{References}

Camerer, C., 1995. "Individual Decision Making"; in: J.H. Kagel and A.E. Roth (Eds.), The Handbook of Experimental Economics, Pinceton: Princeton University Press, 587-703.

Charness, G. and Grosskopf, B. 2001. "Relative Payoffs and Happiness: An Experimental Study"; Journal of Economic Behavior and Organization, 45(3), pp. 301-28.

Dawes, R. M., 1989. "Statistical Criteria for Establishing a Truly False Consensus Effect"; Journal of Experimental Social Psychology 25, 1-17. 
Dawes, R. M., 1990. "The Potential Nonfalsity of the False Consensus Effect"; in: R. M. Hogarth (Ed.), Insights in Decision Making: A Tribute to Hillel J. Einhorn, Chicago: University of Chicago Press.

Engelmann, D. and Strobel, M., 2000. "The False Consensus Effect Disappears if Representative Information and Monetary Incentives Are Given"; Experimental Economics 3, 241-60.

Fischbacher, U., 1999. "Z-Tree, Zurich Toolbox for Readymade Economic Experiments"; Working paper No. 21, Institute for Empirical Research in Economics, University of Zurich.

Forsythe, R., Nelson, R., Neumann, G.R., and Wright, J., 1992. "Anatomy of Experimental Political Stock Markets"; American Economic Review 82, 1142-61.

Friedman, D., 1998. "Monty Hall's three doors: Construction and Deconstruction of a Choice Anomaly"; American Economic Review, 88, 933-46.

Gigerenzer, G., 1991. "How to make cognitive illusions to disappear: Beyond heuristics and biases"; European Review of Social Psychology 2, 83-115.

Heijden, E.v.d., Nelissen, J., and Potters, J., 2003. "Opinions on Tax Deductions and the Consensus Effect in a Survey-Experiment"; Mimeo, Tilburg University.

Hertwig, R. and Ortmann, A., 2001. "Experimental practices in economics: A methodological challenge for psychologists?"; Behavioral and Brain Sciences 24, 383-451.

Jacobsen, E. and Sadrieh, A., 1996. "Experimental Proof for the Motivational Importance of Reciprocity"; University of Bonn, Discussion Paper No. B-386.

Koehler, J.J., 1996. "The Base Rate Fallacy Reconsidered: Descriptive, Normative and Methodological Challenges"; Behavioral and Brain Sciences 19(1), 1-53. 
Krueger, J.I. and Funder, D.C., 2004. "Towards a Balanced Social Psychology: Causes, Consequences and Cures for the Problem-seeking Approach to Social Behavior and Cognition"; Behavioral and Brain Sciences, forthcoming.

Mullen, B., Atkins, J. L., Champion, D. S., Edwards, C., Hardy, D. Story, J. E., and Venderklok, M., 1985. "The False Consensus Effect: A Meta-Analysis of 115 Hypothesis Tests"; Journal of Experimental Social Psychology, 21, 263-83.

Offerman, T., Sonnemans, J., and Schram, A., 1996. "Value Orientations, Expectations and Voluntary Contributions in Public Goods"; The Economic Journal 106, 817-45.

Palacios-Huerta, I., 2003. "Learning to Open Monty Hall's Doors"; Experimental Economics 6, $235-51$.

Ross, L., Greene, D., and House, P., 1977. "The 'False Consensus Effect': An Egocentric Bias in Social Perception and Attribution Processes"; Journal of Experimental Social Psychology $13,279-301$.

Selten, R. and Ockenfels, A., 1998. "An Experimental Solidarity Game”; Journal of Economic Behavior and Organization 34, 517-39.

Slembeck, T. and Tyran, J.-R., 2004. "Do Institutions Promote Rationality? An Experimental Study of the Three-Door Anomaly"; Journal of Economic Behavior and Organization, 54(3), pp. $337-50$. 


\section{A Instructions}

[This is a translated version of the experiment instructions. Paragraphs preceded by a treatment specification in square brackets are only given in the corresponding treatments.]

[Paper instructions, given to the subjects in the beginning of the experiment.]

\section{Instructions}

Welcome to the experiment. Please, read these instructions thoroughly. If something remains unclear to you or if you have a question later on, please raise your hand. We will then approach you and solve the problem. Each of the participants in this experiment has received the same instructions.

In this experiment you will earn an amount of money, which depends on your own decisions, the decisions of the other participants and a random number generator. The earned amount of money will be paid to you in cash straight after the experiment.

We will treat all your decisions as strictly confidential. We will neither tell them to the other participants nor to anybody else.

Please, stop communicating with other participants from now on. If you do not, the data of the experiment will become useless to us, and we would have to exclude you from payment. Also, please switch off your mobile phone.

[Treatments EX and IM]

The experiment at hand consists of two parts. In the first part you have to make a decision which influences your own payoff as well as the payoff of other participants. In the second part we ask you for an estimation. In this part you can improve your own payoff only. Finally there 
will be a questionnaire for statistical data. Detailed instructions for the first part you find below. Further instructions you will get in due time on the screen.

\section{[Treatment BA]}

The experiment at hand consists of two parts. In the first part you have to make a decision which influences your own payoff as well as the payoff of other participants. Moreover we ask

you for an estimate. In the second part we again ask you for an estimation. In this part you can improve your own payoff only. Finally there will be a questionnaire for statistical data. Detailed instructions for the first part you find below. Further instructions you will get in due time on the screen.

\section{Part 1:}

There are 16 persons in total taking part in this experiment. They are divided into groups of four. Thus, you are in a group with three other participants. Neither you nor anybody else will get to know the others' identities. Each participant gets an initial endowment of 10 EURO.

Now, you can decide for or against a lottery. If you decide for the lottery, an amount of 2 EURO is collected from each person in your group (including you). The collected total amount (4 times 2 EURO) will be raised to 10 EURO by the experimenters. This amount will be ra- ed to the participants of your group, i.e. one randomly selected person receives the 10 EURO. Those who had bad luck with the lottery receive nothing and also no compensation for the collected amount of money.

The other group members have to make the same decision. If, for example, all decide against the lottery, then your payoff for Part 1 consists of your endowment of 10 EURO. If, for example, all decide for a lottery, you take part in four lotteries. These lotteries are independent from each 
other, one person can therefore win several lotteries. Your payoff for Part 1 would then consist of 2 EURO plus the possible gains from the four resulting lotteries.

[Treatment BA]

Furthermore we ask you to provide an estimation of how many of the other participants in your group decided for the lottery and how many decided against. If your estimate exactly matches the correct number then you will receive an extra bonus of 5 EURO.

\section{Part 2:}

You will receive the instructions for Part 2 in due time on the screen. In this part, each participant is only able to improve their own payoff.

\section{End:}

Thank you very much for your participation. Please answer the final questionnaire on the screen. Please remain seated and stay quiet until we call you for payment. 


\section{B Computer Screens}

[In the following we report the content of the computer screens as they were presented to the subjects. We report the screens of Treatment BA. For EX and IM subjects received a subset of the information as we will explain with the corresponding screens. "??" is to be substituted by the current information.]

[Screen 1. For Treatments EX and IM, the estimation part was missing.]

Your endowment amounts to 10 EURO. Please decide now whether you want to take part in a lottery. If you opt for the lottery, the payoff of all four persons in your group will be decreased by 2 EURO. In return a prize of 10 EURO is ra- ed to the four persons of your group.

Please, give now an estimation of how the 3 OTHER participants in your group decided. If you exactly match the number you will get a bonus of 5 EURO.

Number of participants opted FOR the lottery Number of participants opted AGAINST the lottery 
[Screen 2. For Treatment EX the last four lines of the upper box were missing. For Treatment

IM only the line starting with "After conducting the lotteries ..." was given in the upper box.]

You have decided against the lottery. From the other participants in your group 2 decided for a lottery and 1 participant decided against a lottery. Thus there were two lotteries conducted in your group. From these you have won 0 and receive 10 EURO for each of them.

After conducting the lotteries your payoff accounts to EURO ??

Your estimate of the number of lotteries chosen by others was ??

Your estimate deviates from the actual number by ??

Thus, you receive a bonus of EURO ??

Your total payoff from the first part of the experiment is EURO ??

Please, give now an estimation of how the 12 participants in the OTHER groups decided. If you exactly match the number you will get a bonus of 15 EURO.

Number of participants opted FOR the lottery Number of participants opted AGAINST the lottery

[Screen 3]

Your estimate of the number of lotteries was ??

The actual number of lotteries in the other groups was ??

Your estimate deviates from the actual number by ??

Thus, you receive for the second part a bonus of EURO ??

Your total payoff accounts to EURO ?? 
CERGE-EI

P.O.BOX 882 Politických vezòù 7

11121 Prague 1

Czech Republic http://www.cerge-ei.cz 